\title{
Further investigation of viewing conditions on standard pseudoisochromatic tests
}

\author{
GERALD M. LONG, BRIAN J. LYMAN, EDWARD P. MONAGHAN, \\ DAVID L. PENN, HOPE A. BROCHIN, AND EDGAR B. MORANO \\ Villanova University, Villanova, Pennsylvania
}

\begin{abstract}
Two experiments are reported that examine the effects of variations in viewing duration, viewing distance, and illumination level on performance with three popular pseudoisochromatic tests of color blindness. Highly significant effects of these conditions are obtained with a sample of color-normal observers, but the three tests also differ markedly in their susceptibility to variations in these viewing conditions. Results are discussed both in terms of practical implications of test administration under nonstandardized conditions and in terms of other likely visual processes assessed by these tests.
\end{abstract}

The best-known methods for the assessment of color vision are the so-called "pseudoisochromatic plates" first developed by Stilling in the 1870 s (see Dimmick, 1943, for a history of early color tests). These plates, in their various published versions, typically require an observer to identify a target stimulus (e.g., a digit) composed of dots of one color embedded in an array of differently colored dots. Adequate color discrimination is necessary in order for an individual to distinguish the target dots from the background dots. Although it is generally acknowledged that other color-screening techniques, such as anomaloscopes and color-arrangement tests, can be more precise, the various pseudoisochromatic tests are nevertheless the most popular of the available screening tests [National Research Council (NRC), 1981]. This popularity is due to their general ease of administration and scoring and their minimal apparatus and training requirements. There are currently three versions of the pseudoisochromatic plates that are widely used in the United States: the American Optical Corporation (AOC) Color Vision Test (Beck Engraving Company, 1965), the Dvorine pseudoisochromatic plates (Dvorine, 1953), and the Ishihara Tests for Color Blindness (Ishihara, 1982). These three tests are routinely administered in a wide variety of industrial, educational, military, and research settings (Birch, Chisholm, Kinnear, Pinckers, Pokorny, Smith, \& Verriest, 1979; NRC, 1981).

The work described in this article is a continuation of recently published research dealing with the effects of viewing conditions on performance with the pseudoisochromatic tests by color-normal observers. Long, Lyman, and Tuck (in press) found that, in general, the three tests are sensitive to variations in viewing duration, viewing distance, and stimulus blur. The number of er-

The authors would like to thank J. Porter Tuck for his helpful discussions of the research reported here. Please send reprint requests to Gerald M. Long, Department of Psychology, Villanova University, Villanova, PA 19085. rors made on the tests increases with decreasing duration, increasing viewing distance, and decreasing stimulus clarity. Furthermore, the tests differ markedly among themselves in their sensitivity to such manipulations, with the Ishihara test being rather insensitive and the AOC and Dvorine tests very sensitive to these effects. From these results, it was concluded that: (1) More standardized viewing conditions are needed for the pseudoichromatic tests, particularly the Dvorine and AOC test, (2) the three popular plate tests are by no means equivalent tests in terms of either baseline performance or susceptibility to viewing effects, and (3) other processes, such as visual acuity, play an important role with such color stimuli. The present article reports two experiments extending this earlier work. In Experiment 1, the effects of target illuminance and target duration are compared over the three pseudoisochromatic tests. In Experiment 2, viewing distance is systematically varied throughout a range from approximately 100 to $450 \mathrm{~cm}(3.8-14.5 \mathrm{ft})$ in order to assess the Long et al. findings at intermediate distances.

\section{EXPERIMENT 1}

This first experiment examined the effects of target illuminance and target duration on performance on three pseudoisochromatic tests. Considerable early work with these tests involved the nature of the illuminant (e.g., Hardy, Rand, \& Ritter, 1946; Schmidt, 1952; Sloan, 1943); and the requirements for the appropriate color temperature of a light source as well as sufficient illumination levels are now generally well known (See Lakowski, 1969). The present work seeks to compare performance on the three tests at two clearly photopic levels of illumination well within the typical working range common for such tests. In addition, the effects of the illumination levels are to be determined at several levels of viewing duration. This latter manipulation of viewing duration partially replicates the conditions examined by Long et al. (in press) but also extends the duration range to very brief 
levels. The effects of these two manipulations of viewing conditions carry both practical and theoretical implications. On the one hand, they may further demonstrate the need for standardized viewing conditions-far more specific than those suggested by the test publishers. On the other hand, they may suggest the nature and role of other processes that have been hypothesized to be assessed by the color plates.

\section{Method}

Subjects. Forty-two subjects ( 12 males) participated in partial fulfillment of a course requirement in general psychology at Villanova University. Only individuals with no known color problems were asked to volunteer. In addition, before participation in the experiment, each observer was further screened on the Farnsworth D-15 color-arrangement test (see Linksz, 1966) and with two items (Plates 14 and 15) from the Ishihara test that contain "hidden digits" theoretically observable only by color-defective observers. No volunteers had to be excluded because of any difficulty with these prescreening measures. Each observer participated individually in a single experimental session lasting 20-30 min.

Apparatus and Procedure. With the single restriction that there be the same numbers of each sex per condition, each observer was assigned randomly to one of six possible viewing conditions defined by the factorial combination of two illuminance levels $(75$ and $750 \mathrm{~lx})$ and three viewing durations $(.5,1.0$, and $3.0 \mathrm{sec} /$ plate $)$. A chin-and-headrest was used to maintain a constant viewing distance of $75 \mathrm{~cm}$. An Ealing electronic shutter (Model 22-8437) controlled by a Hunter timer (Model 100C) was mounted about $15 \mathrm{~cm}$ in front of the observer's right eye, and the plates were positioned $60 \mathrm{~cm}$ behind the shutter and were clearly viewed through the 6-cm shutter aperture. A 35- $\mathrm{mm}$ clear glass slide served as a beam splitter and was positioned between the observer's eye and the shutter; a red fixation point located $75 \mathrm{~cm}$ from the observer's eye was reflected in the beam splitter. This served to maintain the observer's accommodation for the appropriate $75-\mathrm{cm}$ target distance even when the shutter aperture was closed prior to target presentation.

Two side-by-side Macbeth easel lamps (Macbeth Corporation) provided illumination of the test plates. A 1.0 ND filter (Kodak 96) could be placed in front of the observer's eye to vary retinal illumination. The effective illuminance of the plates was either $750 \mathrm{~lx}$ without the filter or $75 \mathrm{~lx}$ with the filter. The illuminance level recommended by Lakowski (1969) for the pseudoisochromatic tests is about $300 \mathrm{~lx}$ (28 fc). Hence, the two levels employed in this work, although both clearly photopic, represent significant departures from the recommended value.

For each observer, the same 14 plates were used from each of the three pseudoisochromatic tests: Plates 2-15 on the AOC, Plates 2-15 on the Dvorine, and Plates 2-13, 16, and 17 on the Ishihara (see Long et al., in press). On each trial, the observer was given a verbal "ready" signal, and the shutter then opened for the appropriate duration. The observer reported verbally the digit he/she saw on the plate, and the experimenter recorded this value before proceeding to the next trial. No feedback was given to the observer concerning his/her accuracy. To familiarize the observer with the task, Plate 1 from each test, the "practice" plate, was given prior to the 42 test plates in the session.

\section{Results and Discussion}

The mean number of errors obtained on the three pseudoisochromatic tests are shown in Figure 1 as a function of viewing duration. The upper portion of Figure 1 corresponds to the low-illuminance condition, and the lower portion to the high-illuminance condition. A 3 (tests) $\times$ 3 (durations) $\times 2$ (illuminance) mixed analysis of variance reveals significant main effects of tests $[F(2,72)=$ $157.10, \mathrm{p}<.0001]$, duration $[\mathrm{F}(2,36)=15.04, \mathrm{p}<$ $.0001]$, and illuminance $[\mathrm{F}(1,36)=21.49, \mathrm{p}<.0001]$. These effects can clearly be seen in Figure 1. Also evi-

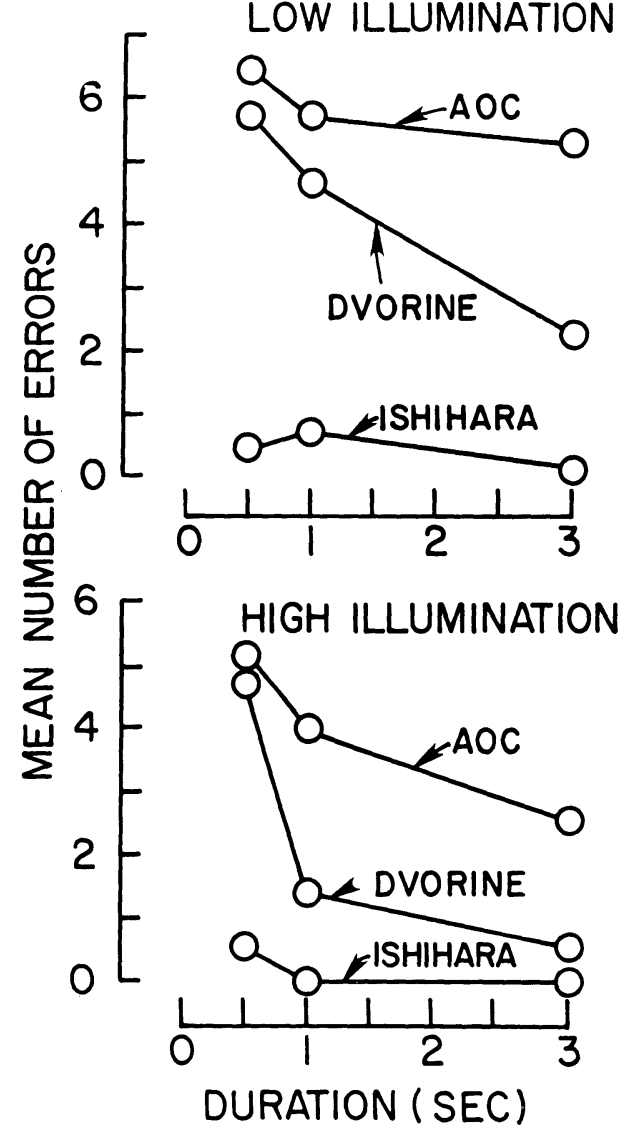

Figure 1. Mean number of errors on the three pseudoisochromatic tests as a function of viewing duration under the low illumination level (upper graph) and the high illumination level (lower graph).

dent in Figure 1 are the significant tests $\times$ duration interaction $[F(4,72)=7.03, p<.0001]$ and the significant tests $\times$ illumination interaction $[\mathrm{F}(2,72)=7.47, \mathrm{p}$ $<.001]$. No other interactions are significant.

From these analyses, it is clear that, in general, fewer errors are made on the pseudoisochromatic tests with the higher level of illumination and as viewing duration is increased. The latter finding replicates and extends the results of Long et al. (in press) concerning strong duration effects on these tests. The former finding is consistent with Lakowski's (1969) recommendation for relatively high photopic levels on the tests. Of particular interest in the present work are the significant patterns of interaction obtained. These interactions indicate that the tests differ markedly among themselves in their susceptibility to the variations in viewing conditions. The Ishihara test in particular is relatively insensitive to such variations.

\section{EXPERIMENT 2}

The previously mentioned study by Long et al. (in press) examined the effect of varying viewing distance over the levels of $46 \mathrm{~cm}$ (reading distance), $75 \mathrm{~cm}$ 
(recommended distance), and $305 \mathrm{~cm}$. The final value was chosen arbitrarily as an upper extreme that would rarely, if ever, be encountered under actual conditions of test administration. Although both the AOC and the Dvorine tests were significantly affected by this distance manipulation, the possibility exists that the obtained effect may be due largely to the extreme upper value selected. The present experiment examined the effects of intermediate distances to ensure that the distance effect reported by Long et al. could be generalized over a more representative range of viewing distances.

\section{Method}

Subjects. Forty-five subjects ( 37 female) participated in partial fulfillment of a course requirement in general psychology at Villanova University. Only individuals who had no known color difficulties were asked to volunteer.

Apparatus and Procedure. The same three color tests from Experiment 1 were employed. The tests were presented by an experimenter standing at the front of a classroom with curved and tiered seating. The observers were seated only in the first five rows; mean viewing distances from the tests were $116,176,298,374$, and $440 \mathrm{~cm}(46,69$, 117,147 , and 174 in.). All viewing was done with a Macbeth easel lamp, as recommended by the test publishers, and viewing time was held constant at $3 \mathrm{sec} /$ plate. On each trial, the observer simply recorded on an answer sheet the digit contained on the test plate.

\section{Results and Discussion}

The mean numbers of errors reported for the three pseudoisochromatic tests are shown in Figure 2 as a function of viewing distance. A 3 (tests) $\times 5$ (distance) mixed analysis of variance reveals a significant main effect of tests $[F(2,80)=80.78, p<.0001]$ and viewing distance $[\mathrm{F}(4,40)=7.58, \mathrm{p}<.0001]$. The interaction of tests $X$ distance is also significant $[F(8,80)=2.18, p<.04]$, which results from the somewhat more pronounced effect of varying distance on the AOC and Dvorine tests than on the Ishihara test.

The significant differences among the three plate tests replicates those found by Long et al. (in press). As they reported, the AOC test results in the greatest number of errors, and the Ishihara test in the fewest. The significant distance effect reveals a largely linear increase in errors with increasing viewing distance. This finding extends the results of Long et al., who obtained very similar effects but with just the extreme viewing distances.

\section{CONCLUSION}

The results of the present work have both practical and theoretical implications for the screening of color vision. On the practical level is the obvious need for standardization of test conditions-particularly in applied settings in which such conditions may be expected to vary widely. In conjuction with the Long et al. (in press) study, the results of the present experiment make clear that variations in viewing distance, viewing duration, stimulus clarity, and stimulus illuminance can seriously influence performance on the tests even among color-normal observers. It is equally clear that the three pseudoisochromatic tests are very different from one another. Not only do the tests differ in the level of errors made by the same individual, but they also are differentially sensitive to variations in viewing conditions. Both the AOC test and the Dvorine test are much more seriously affected by these conditions than is the Ishihara test.

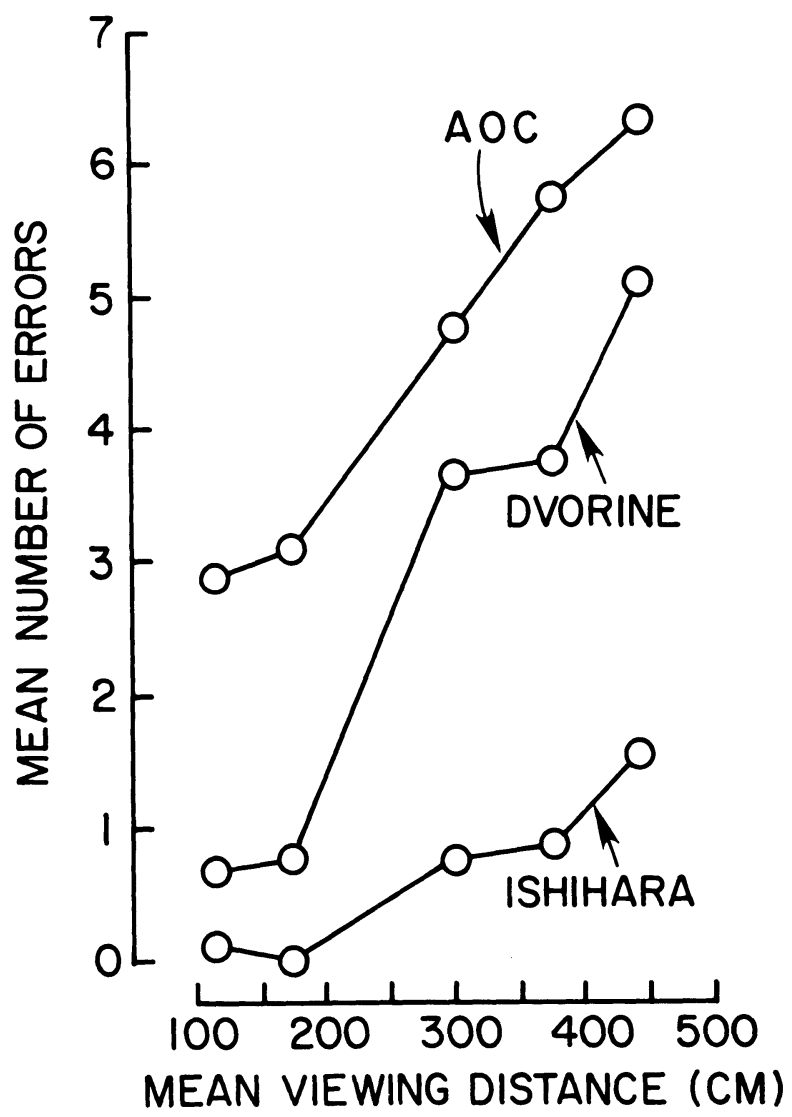

Figure 2. Mean number of errors on the three pseudoisochromatic tests as a function of viewing distance.

On the theoretical level, the present results raise the issue of other visual processes that may be involved in performance with pseudoisochromatic stimuli. One likely possibility is visual acuity, which would be sensitive to the manipulations employed in this study as well as in Long et al. (in press). Other investigators have noted that visual acuity is correlated with performance on the pseudoisochromatic tests (e.g., Holland, 1972) as well as other color-vision tests (Brown, Govan, \& Block, 1983). There are other likely visual processes involved on the tests as well. For example, the extent of visual scanning on the individual plates would also be affected by many of the same variations in viewing condition (e.g., duration, distance). The identification of these additional visual processes is important, not only for the eventual development of "purer" color-screening tests, but also for the realization of the needed caution when the current tests are administered in situations in which these other processes may seriously differ among the individuals examined. This could include work with aged subjects (e.g., Lakowski, 1958, 1962), with young children (e.g., Alexander, 1975; Lampe, 1969), with the mentally retarded (e.g., Salvia, 1969; Salvia \& Ysseldyke, 1971), and with individuals suffering form various visual pathologies (e.g., Grutzner, 1972; Verriest, 1963). The oft-reported performance differences by these groups on the pseudoisochromatic plates may reflect differences in other visual processes beyond color vision.

\section{REFERENCES}

Alexander, K. R. (1975). Color vision testing in young children: A review. American Journal of Optometry and Physiological Optics, 52, 332-337.

Beck Engraving Company. (1965). American Optical Corporation pseudo-isochromatic plates for testing color vision. Philadelphi: Author. 
Birch, J., Chisholm, I. A., Kinnear, P., Pinckers, A. J., Pokorny, J., SMith, V. C., \& VerRIEst, G. (1979). Clinical testing methods. In J. Pokorny, V. C. Smith, G. Verriest, \& A. J. Pinckers (Eds.), Congenital and acquired color vision defects. New York: Grune \& Stratton.

Brown, L., Govan, E., \& Block, M. T. (1983). The effect of reduced acuity upon Farnsworth 100-hue test performance. Ophthalmic and Physiological Optics, 3, 7-11.

Dimmick, F. L. (1943). Methodology and test preparation. Journal of the Optical Society of America, 33, 308-315.

Dvorine, I. (1953). Dvorine pseudo-isochromatic plates. New York: The Psychological Corporation.

GrUTZNER, P. (1972). Acquired color vision defects. In D. Jameson \& L. M. Hurvich (Eds.), Handbook of sensory physiology: Vol. 7/4. Visual psychophysics. Berlin: Springer-Verlag.

HARDY, L. H., RAND, G., \& RitTleR, M. C. (1946). The effect of quality of illumination on the results of the Ishihara test. Journal of the Optical Society of America, 36, 86-94.

Holland, P. M. (1972). Adult color vision screening: A comparison of stereoscopic vision tester slide with Ishihara plates. Archives of Ophthalmology, 88, 613-616.

IsHIHARA, S. (1982). The series of plates designed as a test for colourblindness. Tokyo: Kanehara.

LAKOWSKI, R. (1958). Age and colour vision. Advancement of Science, 15, 231-236.

LAKOWSKI, R. (1962). Is the deterioration of colour discrimination with age due to lens or retinal changes? Farbe, 11, 69-86.

LAKOWSKI, R. (1969). Theory and practice of colour vision testing: A review, Part 1. British Journal of Industrial Medicine, 26, 173-189.
LAMPE, J. M. (1969). An evaluative study of color-vision tests for kindergarten and first grade pupils. Journal of School Health, 39, 311-314.

LinKsz, A. (1966). The Farnsworth Panel D-15 test. American Journal of Ophthalmology, 62, 27-37.

LoNG, G. M., Lyman, B. J., \& TuCK, J. P. (in press). Distance, duration, and blur effects on the perception of pseudiosochromatic stimuli. Ophthalmic and Physiological Optics.

National Research Council (Committee on Vision). (1981). Procedures for testing color vision (Report of Working Group 41). Washington, DC: National Academy Press.

SalviA, J. (1969). Four tests of color vision: A study of diagnostic accuracy with the mentally retarded. American Journal of Mental Deficiency, 74, 421-427.

SALVIA, J., \& YSSELDYKe, J. (1971). An analysis of the reliability and validity of the Ishihara color plates with mentally retarded males. Perceptual and Motor Skills, 33, 243-246.

ScHMIDT, I. (1952). Effect of illumination in testing color vision with pseudo-isochromatic plates. Journal of the Optical Society of America, 42, 951-955.

SloAN, L. (1943). Daylight fluorescent lamp as a source of illumination in tests of color perception with pseudoisochromatic plates. (Project 130, Rep. No. 1). Randolph Field, TX: School of Aviation Medicine.

VERRIEST, G. (1963). Further studies on acquired deficiency of color discrimination. Journal of the Optical Society of America, 53, 185-195.

(Manuscript received for publication June 15, 1984.) 